\title{
QUANDO A HISTÓRIA ENCONTRA O CORPO: INTERFACE ENTRE OS “DESLOCAMENTOS" FOUCAULTIANOS E A ICONOCLASTIA KAFKIANA ${ }^{a}$
}

\author{
When the History meets the Body: Interface between the \\ Foucaul's "Dislocations" and the Kafka's Iconoclast \\ Cuando la Historia Encuentra el Cuerpo: Interfaz entre \\ los "Dislocamientos" Foucaultianos y la Iconoclastia Kafkiana
}

Nei Antonio Nunes ${ }^{1}$

\section{Resumo}

Neste ensaio, partindo dos deslocamentos empreendidos pela genealogia foucaultiana na pesquisa histórica, propõe-se a análise da noção de acontecimento. Para tanto, recorre-se não só à produção filosófica de Foucault, mas também à genealogia de Nietzsche. Após a apresentação desses "procedimentos de investigação", analisaram-se duas novelas de Franz Kafka, A metamorfose e Na colônia penal. Na interface entre filosofia e literatura, entre os deslocamentos propostos por Foucault na pesquisa em história e a iconoclastia expressa no texto kafkiano, buscou-se identificar, por exemplo, como o corpo aparece, em tantos momentos, na trama contemporânea e, assim, no universo desnudado por esses pensadores. É justamente aqui que se procurou, com base na crítica dos autores em questão, examinar acontecimentos que possam ter pertinência à pesquisa em história da enfermagem.

Palavras-chave: História. História da Enfermagem. Filosofia. Pesquisa.

\begin{abstract}
In this Essay, from the dislocations that happened in the Foucault's genealogy in the History Research, it is proposed the analyses of the notion of happenings. For that, it has to recourse itself not only to the philosophical production of Foucault, as also to the Nietzsche genealogy. After the presentation of these "procedures of investigation", it was analyzed two novels of Franz Kafka, The Metamorphosis and In the Penal Colony. In the interface between philosophy and literature, between the dislocations proposed by Foucault in the research in the History and the iconoclast expressed in the Kafka's text, it searched to identify, for example, as the body appears, in many moments, in the contemporary plot and, thus, in the denude universe by these thinkers. It is here where it was searched, based in the author critic, to exam the happenings that might be important to the research in Nursing History.
\end{abstract}

\section{Resumen}

En este ensayo, partiéndose de los dislocamientos emprendidos por la genealogía foucaultiana en la investigación histórica, se propone un análisis acerca de la noción de acontecimiento. Para tanto, se recurre no solamente a la producción filosófica de Foucault, sino también a la genealogía de Nietzsche. Después de la presentación de esos "procedimientos de investigación", se analizaron dos novelas de Franz Kafka, La metamorfosis y $L a$ colonia penal. En la interfaz entre filosofía y literatura, entre los dislocamientos propuestos por Foucault en su investigación en historia y la iconoclastia expresa en el texto kafkiano, se ha buscado identificar, por ejemplo, cómo el cuerpo aparece, en tantos momentos, en la trama contemporánea y, así, en el universo desnudo por esos pensadores. Es precisamente aquí que se ha procurado, con base en la crítica de los autores en cuestión, examinar acontecimientos que puedan tener pertinencia en la investigación en historia de la enfermería. 


\section{MOTIVAÇÕES}

Quando pensei nas questões que discutiria no $2^{\circ}$ Colóquio Latino-Americano de História da Enfermagem - Evento realizado, em 2005, pelo Núcleo de Pesquisa de História da Enfermagem Brasileira (Nuphebras) da Escola de Enfermagem Anna Nery -, instigado pelo tema "A construção do saber na história da enfermagem", fiz o esforço de procurar em minhas reminiscências as primeiras experiências que tive com a história como saber. Assim, recorrendo à memória, naquilo que pode contribuir para história, lembrei que por volta dos 12 anos de idade vivi uma experiência singular: meus pais eram donos de um pequeno armazém no subúrbio da cidade de Florianópolis. Esta vendinhaera assim que os freqüentadores denominavam o tal estabelecimento comercial - funcionava também como bar durante as noites. Nos períodos em que eu não estava na escola, fazendo as tarefas ou mesmo brincando, ajudava meus pais neste comércio.

Dessa época de minha vida, tenho especial lembrança de que os momentos que antecediam o meio-dia, como também após às 18 horas, eram para mim os mais animados nesse trabalho. Isto porque a venda ficava cheia. Lá, muito se conversava. Entre um gole e outro, peões, funcionários públicos, estudantes universitários, ou mesmo desocupados, travavam os mais acalorados debates. Recordo que em uma das noites em que estava trabalhando algo despertou sobremaneira minha atenção e, assim, ainda mais minha curiosidade: em meio à conversa solta e entusiasmada dos freqüentadores do bar, um sujeito, com ar resoluto e voz firme, leu algo extraído de um dos jornais que estavam dispostos sobre o balcão. Com base nas informações sobre acontecimentos recentes - o conteúdo da matéria tratava de alguma questão ligada à abertura política no Brasil - este indivíduo propunha temas para 0 debate conjeturando proposições polêmicas, o que só fez aumentar a contenda.

Nesse cenário tão rico e diversificado creio que vivenciei pela primeira vez como sujeito - um tanto estupefato - uma singular experiência de conflito na ordem do saber. Esta sensação fora provocada pela magnitude do entrecruzamento entre a grandiloqüência dos fatos narrados nas páginas principais de um periódico e os fantásticos relatos, também cotidianos, das vidas destes homens e mulheres que freqüentavam o armazém.

Aliás, nessa atividade, testemunhei diversas situações nas quais a vida era desvelada para mim, no entrecruzamento entre a rudeza e a sensibilidade presente na simplicidade das pessoas. Assim, indivíduos recostados no balcão, às vezes em voz alta e com orgulho ou timidamente quase em tom de confissão, contavam momentos de suas histórias pessoais, revelando seus feitos, mas também suas origens, seus hábitos, costumes e valores, suas esperanças e seus desencantos. Hoje, longe daqueles dias, fico me questionando sobre o valor antropológico e social daquelas histórias.

Em meio às confusões próprias da idade de alguém que ainda se esforçava para fazer a transição - como dirá Kant da heteronomia para autonomia, eu perguntava, singelamente, se seria possível a relação entre estas duas formas de experiência - os grandes conteúdos dos periódicos e as trajetórias de muitas daquelas vidas simples. Distante desses dias, percebo a complexidade do cenário que propõe, ao mesmo tempo, identidades e estranhamentos. Entre os periódicos e as narrativas individuais, arrisco dizer que não havia o conforto das continuidades, mas uma relação tensa, muitas vezes complementar, noutras, expressão de ruptura, diferença e até mesmo de resistência.

Percebo que o desejo de propor esta reflexão como um ensaio expressa duas motivações que, quem sabe, sejam complementares: primeiramente, evitando o "solipsismo", destacar que a história também pode tratar dos acontecimentos marginais, creio, reveladores de tantos "silêncios"; segundo, o meu anseio de vivenciar novas experiências e/ou caminhos na investigação filosófica. Dupla motivação que me levou a sugerir neste texto uma reflexão a partir dos deslocamentos propostos pelas análises genealógicas de Michel Foucault (1926-1984) e das novelas $A$ metamorfose e Na colônia penal de Franz Kafka (1883-1924), marcadas pela irreverência intelectual. A escolha destes pensadores objetiva, primeiro, chamar atenção para o valor epistemológico de objetos de estudo e áreas do conhecimento nem sempre contemplados pelos paradigmas científicos contemporâneos; segundo, destacar os esforços já empreendidos na pesquisa em história - como os trabalhos realizados por pesquisadores do Núcleo de Pesquisa de História da Enfermagem da Escola Anna Nery -, sem desconsiderar a contribuição de qualquer corrente filosófica ou literária da tradição ocidental que tenha contribuído com a Historiografia.

\section{MICHEL FOUCAULT "RE-VISITANDO" NIETZSCHE. GENEALOGIAS: HISTÓRIA CRÍTICA COMO HISTÓRIA DOS ACONTECIMENTOS}

Embora não seja considerado historiador no sentido usual do termo, sabemos que a pesquisa histórica se constituiu num elemento-chave na trajetória intelectual de Michel Foucault. Apesar das diferenças no campo de análise, da obra História da loucura (1961) ao Cuidado de si (1984), passando pelos cursos do Collège de France, o filósofo nunca deixou de fazer uso da história. As "ferramentas" utilizadas pelo pensador francês em suas pesquisas - a exemplo dos conceitos extraídos do pensamento nietzschiano - foram como pincéis operados pelas mãos de um hábil pintor, mas que ganharam sentido, cabe destacar, na tela da história.

Como sabemos, o termo genealogia, significando o empreendimento de uma análise histó-rica e crítica, foi apresentado primeiramente por Friedrich Nietzsche (18441900). Ao discutir os temas do ressentimento, da máconsciência e do ideal ascético nas três dissertações que constituem os eixos centrais da Genealogia da moral, Nietzsche, no ano de 1887, faz uma crítica radical dos valores morais dominantes na sociedade moderna. Nestas três dissertações dedicadas à crítica genealógica da moral, a saber, crítica à moral do ressentimento (cristianismo), crítica à mo-ral autônoma, auto-consciente (Kant) e crítica ao ideal ascético (niilismo), o pensador alemão propõe de forma metódica 0 projeto de transvaloração como nova exigência para a autosuperação do homem moderno, condição necessária para afirmação da vida - constituída no plano da imanência - que deve realizar-se como "vontade de potência". Em outros termos, diz Nietzsche que é imperativo uma crítica dos valores morais, 
por meio da qual o próprio valor desses valores seja questionado. Vale ressaltar que a história e a filologia são instrumentos utilizados pelo autor para empreender uma crítica radi-cal sobre a própria história, ou melhor dizendo, sobre a maneira usual como foi concebida por muitos historiadores no século XIX.

Em sua história da moral, Nietzsche procura colocar em relevo a "moral que realmente houve, que realmente se viveu - com novas perguntas, com novos olhos...". Nesse intento, a pesquisa genealógica buscava "a coisa documentada, o efetivamente constatável, o realmente havido, numa palavra, a longa, quase indecifrável escrita hieroglíica do passado moral humano!" (Nietzsche ${ }^{1: 13}$ ). Esclarece Machado que o projeto genealógico de Nietzsche é uma tentativa de superação da metafísica por meio de uma história descontínua dos valores morais, procurando investigar sua origem - entendida como nascimento, invenção - como também os valores desses respectivos valores (Machado 2:59).

Cabe acrescentar que num livro anterior à Genealogia da moral, escrito em 1873 e intitulado Segunda consideração intempestiva - da utilidade e desvantagem da história para vida, Nietzsche, ao sustentar a vinculação entre a história como saber e a vida - caracterizando esta última a partir de um complexo campo de relações de força -, salienta que o conceito de história em alemão (Geschichte) deriva originariamente do termo "acontecimento" (Geschehnis). Possivelmente dessa vinculação possamos inferir que uma determinada concepção de história que não possibilite, para além de surpreender seus interlocutores, ser surpreendida pelos acontecimentos estaria em contradição com o próprio sentido etimológico e epistemológico (Nietzsche 3:42-44).

Como nos diz Marton ${ }^{4: 36}$, a influência da obra do filósofo alemão no pensamento de Foucault vai muito além da utilização, por parte do pensador francês, do termo genealogia para definir os novos rumos e procedimentos de suas pesquisas. 0 desinte-resse de Foucault por uma obra sistemática, a sua opção na pesquisa pelo primado da relação sobre o ob-jeto, bem como a valorização decisiva dada à interpretação e aos procedimentos estratégicos em suas análises genealógicas revelam, sobremaneira, o legado nietzschiano presente - não sem variações - nos escritos genealógicos de Foucault.

Por sua vez, não se trata de reconhecer em Foucault um comentador de Nietzsche ou um continuador de sua obra. Foucault utiliza os conceitos do filósofo alemão como um preci-oso instrumento para suas análises, sendo a crítica genealógica nietzschiana uma espécie de "caixa de ferramentas" utilizada em suas investigações genealógicas.

É no artigo "Nietzsche, a Genealogia, a História" que Foucault discute com maior profundidade os impactos da genealogia de Nietzsche na pesquisa histórica. Nesse texto, ficam evidenciados tanto a importância dada por Foucault à genealogia nietzschiana quanto o uso que o filósofo francês faz desse valioso instrumento em sua genealogia crítica. Segundo Fou-cault, Nietzsche sustenta em sua genealogia que a pesquisa histórica não deve ser reduzida às categorias de continuidade e evolução. Com isso, acrescenta Foucault, 0 autor ale-mão teria afirmado a centralidade do conceito de aconte-cimento para a história genealógica:

É preciso entender por acontecimento não uma decisão, um tratado, um reino, ou uma batalha, mas uma relação de forças que se inverte, um poder confiscado, um vocabulário retomado e voltado con-tra seus utili-zadores, uma dominação que se enfraquece, distende, se envenena e uma outra que faz sua entrada, masca-rada. (...) Mas o verdadeiro sentido histórico reconhece que nós vivemos sem refe-rências ou sem coordena-das originárias, em miríades de acontecimentos perdidos (Foucault:28,29).

Cumpre observar que Foucault recorre a Nietzsche para demonstrar que as longas e gran-diloqüentes narrativas históricas e suas linearidades - com personalidades e fatos históricos deci-sivos na definição dos traços gerais dos grandes períodos - não só não dão conta de uma gama considerável de "pequenos acontecimentos históricos", como igno-ram sua importância e riqueza para uma leitura crítica da história. Em outras palavras, o recurso a Nietzsche indica que investigar as marcas diferenciais na história é empreender o projeto de trazer à tona a intrincada trama das lutas, das intenções, dos menores desvios, das múltiplas forças sociais e dos acidentes decisivos em nossa história, que fogem ao alcance, muitas vezes, das grandes narrativas históricas.

No artigo "Verdade e Poder", Foucault alerta para a complexidade das pesquisas que se centralizam nos acontecimentos:

Não se trata de colocar tudo num certo plano, que seria o do acontecimento, mas de considerar que existe todo um escalonamento de tipos de acontecimentos diferentes que não têm o mesmo alcance, a mesma amplitude cronológica, nem a mesma capacidade de produzir efeitos.

Oproblema é ao mesmo tempo distinguir os acontecimentos, diferenciar as redes e os níveis a que perten-cem e reconstituir os fios que os ligam e que fazem com que se engendrem, uns a partir dos outros (Foucault:5:5).

A genealogia crítica destes "acontecimentos menores", sustentada por Foucault, procura fazer com que se manifeste todo um importante campo de ações e de inteligibili-dade, mantido na obscuridade e no silêncio por algumas macroanálises da história. Assim, a investigação dos acontecimentos deve detectar e pôr em evidência toda uma teia bastante complexa e multi-forme de relações de força sociais, colocando em relevo os momentos das configurações dessas relações. Para essa investigação, Foucault utiliza os recursos de análise - segundo ele nietzschianos - definidos como proveniência e emergência.

A proveniência procura as marcas diferenciais na história, os desvios, os aciden-tes; ela realiza a tarefa de inventariar as inúmeras heterogeneidades decisivas na constitui-ção histórica dos indivíduos, de seus sentimentos, de suas idéias. Nesta perspectiva, não se trata de encontrar simplesmente na semelhança generalizável o elo de ligação entre o passado e a atualidade, sua chave de inteligibilidade ou seu fundamento. Pelo contrário. Conforme Marton ${ }^{4: 39,40}$, são as diferenças, muitas vezes despercebidas, os alvos privilegiados das proveniên-cias 
dos acontecimentos históricos. Ao analisar as heterogeneidades dos aconteci-mentos e privilegiar as marcas diferenciais na História, segundo Foucault, Nietzsche não só teria criticado a segurança que envolve as noções de objetividade, de se-melhança e de uni-versalidade, como também a crença absoluta na exatidão dos fatos, como sabemos, tão usuais nas ciências e em certas teorias da história no século XIX.

A pesquisa da proveniência não funda, muito pelo contrário: ela agita o que se percebia imóvel, ela frag-menta o que se pensava unido; ela mostra a heterogeneidade do que se imaginava em conformidade consigo mesmo (Foucault:21).

Junto à proveniência, Foucault sustenta que Nietzsche utiliza a emergência como recurso na análise dos acontecimentos. A emergência se define pelo ponto de surgimento dos valores e costumes. É o campo em que as forças surgem, e ao analisá-lo o pensador alemão teria procurado identificar o estado de forças que dá condições ao seu aparecimento. Seria um equívoco tentar compreender a emergência com base numa teleo-logia ou numa causalidade. Foucault afirma que a investigação filológica e histórica, constitutiva da genealogia de Ni-etzsche, mostra a articulação entre proveniência e emergência. A genealogia de Nietzsche é assim definida por Foucault como análise das proveniências e história das emergências.

Foucault vê como grande legado e inovação do pensa-mento ni-etzschiano a inauguração de uma nova hermenêutica. Nietzsche teria feito da pesquisa histórica uma interpretação constante de interpretações, procurando empreender, desta forma, uma investigação que não negligenciasse as inúmeras possibilidades de perspectivas na leitura da história. Neste sentido, a genealogia de Nietzsche seria uma interpretação histórica e filológica - sem a preocupação, e por que não dizer, sem a pretensão de um ponto de chegada definitivo.

Foucault assume estes recursos - a proveniência e a emergência - em sua crítica genealó-gica das práticas históricas e sociais de poder. Trata-se de inquirir nas relações de força, nas práticas dos poderes e dos saberes, nos exercícios de subjetivi-dade e nas estratégias de dominação, na objetivação e subjetivação dos corpos individuais e populacionais, suas proveniências e emergências. Procurando, desta forma, fazer um inventário histórico-crítico dos acontecimentos - desde as suas menores configurações - a partir dos múltiplos elemen-tos diferenciais que marcam seus surgimentos. Não se trata, contudo, de tornar os acontecimentos uma categoria absoluta ou de totalizar as diferenças como a única verdade histórica, mas de reconhecer as marcas diferenciais como elementos indispensáveis no estudo crítico da história.

É nessa perspectiva que o filó-sofo francês discute a modernidade e analisa o surgi-mento do dispositivo disciplinar, com base numa microfísica do poder, e do dispositivo de sexualidade a partir de uma analí-tica interpretativa do poder. Com base nestes dispositivos históricos, o filósofo empreende uma crítica às práticas de "objetivação" e "subjetivação", as quais os corpos individuais e sociais foram, em tantos momentos e nos mais diferentes espaços, sujeitados.
A genealogia seria, pois, relativamente ao projeto de uma inserção dos saberes na hierarquia do poder próprio da ciência, uma espécie de empreendimento para dessujeitar os saberes históricos e torná-los li-vres, isto é, capazes de oposi-ção e de luta contra a coerção de um discurso teórico uni-tário, formal e ci-entífico. A reativação dos sa-beres locais - 'menores', talvez dissesse Deleuze - contra a hierarquização ci-entífica do conhecimento e seus efeitos intrínsecos, esse é o projeto des-sas genealogias em desordem e picadinhas. Eu diria em duas palavras o seguinte: a arqueologia se-ria o método próprio da análise das dis-cursividades locais, e a genealogia, a tática que faz intervir, a partir dessas discursividades locais assim descritas, os saberes dessujeitados que daí se desprendem. Isto para reconstituir o projeto de conjunto (Foucault ${ }^{6: 15,16}$ ).

Para Lebrun, diferentemente de um pensador moderno como Thomas Hobbes (1588-1679), que oferecia sua Teoria Política como uma espécie de telescópio que possibilitasse compreender a natureza e a utilidade da soberania, Foucault "põe em nossas mãos um microscópio que nos fará penetrar até 'o infinitamente pequeno do poder político' e descobrir, por baixo das instituições e aparelhos de Estado, o formigamento dos micropoderes, a abundância dos 'minúsculos' mecanismos disciplinares..." $\left(\right.$ Lebrun $\left.^{7: 81}\right)$. Acredito que a figura do caleidoscópio possa ser mais apropriada para uma analogia com o tipo de investigação que Foucault realiza na genealogia. Isso porque o microscópio - pelo menos um modelo simples - é um instrumento óptico destinado exclusivamente à observação e ao estudo de objetos de dimensões muito pequenas; já a genealogia como pesquisa histórica não parte unicamente da amplia-ção de minúsculos pontos, pouco perceptíveis, nos quais, por exemplo, os poderes sociais agiriam. Diferente disso, trata-se, nesse campo de investigação, de ligações móveis, instáveis e não-localizáveis.

0 caleidoscópio - pequeno instrumento cilíndrico possibilita a observação das múltiplas configurações do objeto analisado a partir das mudanças tanto do objeto quanto da posição do olhar do observador: diferentes olhares atentos do "genealogista-historiador" e alterações na configuração dos espelhos - novas possibilidades de interpretação, novas perspectivas - procurando, como experiência na ordem dos saberes, capturar a sucessão rápida e cambiante das relações histórico-sociais, epistemológicas, éticas e políticas. Depreendese disto o importante desafio do pesquisador em História de Enfermagem de continuar valorizando as marcas diferenciais nos procedimentos investigativos e nos objetos pesquisados.

\section{KAFKA E OS "ACONTECIMENTOS” NA HISTÓRIA}

Sabemos que muito já foi dito a partir de importantes estudos sobre o vigor do pensamento kafkiano. Aliás, não só para literatura, mas também para os diferentes saberes que constituem as Ciências Humanas. Sem a pretensão de propor um ponto de vista original nesta investigação, gostaria, mesmo que de forma introdutória, discutir a pertinência das duas novelas de Kafka para nossas pesquisas em história. Para tanto, 
sugiro começarmos ampliando a provocação proposta por Albuquerque Junior aos historiadores: o que podem aprender os historiadores da Enfermagem lendo Kafka? Ele responde: talvez Kafka ajude os historiadores a melhor valorizar o acontecimento na história. E acrescenta: "Kafka parece falar, em suas obras, deste devir que capta ao seu redor. Suas histórias parecem nos ensinar que uma das tarefas do historiador é mapear, no presente, as suas virtualidades, seus devires, os futuros possíveis que contêm em potência" (Albuquerque Junior ${ }^{8: 13 ; 23-25}$ ). A esta proposição acrescento: a referência a Kafka sugere a consideração na pesquisa histórica da Enfermagem de elementos como o estranhamento, a diferença e a multiplicidade. É nesta perspectiva que proponho algumas considerações sobre o "universo kafkiano".

Tratando especificamente das duas novelas e de forma bastante resumida, A metamorfose, escrita em 1912, fala da transformação de Gregor Samsa, um jovem caixeiro-viajante, em um inseto gigante e, em decorrência, dos dramas que se sucederam em sua vida. Já a novela intitulada Na colônia penal, de 1914, apresenta o cotidiano de uma colônia penal e suas vicissitudes a partir da visita de um estrangeiro.

Kafka9:7 inicia A metamorfose afirmando: "Quando certa manhã Gregor Samsa acordou de sonhos intranqüilos, encontrou-se em sua cama metamorfoseado num inseto monstruoso. (...) - 0 que aconteceu comigo? - pensou". Kafka utiliza-se nessa novela da narração para vaguear do fictício ao verossímil e vice-versa. Kafka não dá esperanças a Gregor, e este, por sua vez, não dá esperanças a si mesmo. A metamorfose é irreversível e Schwarz ${ }^{10: 47}$ acrescenta: "o caso começa mal e acaba pior! Não se trata de estória da carochinha ou de estória pra boi dormir." A transformação de Gregor, a nova aparência, a deterioração do corpo são inexoráveis. Irreversíveis também são os limites da liberdade e da consciência do caixeiro-viajante. Aliás, rastejar, alimentar-se de restos de comida em estado de putrefação e horrorizar aos outros com sua aparência, são associados também a ausência de variação no tempo. Para Gregor, ontem, hoje, amanhã, depois, tanto faz, pois nada pode mudar.

Como se não bastasse o novo corpo de inseto, a linguagem de Gregor Samsa já não mais existe; agora o que predomina é um "pipilo", primitivo em sua essência e imperceptível aos homens. Com a falta de comunicação, a família perde a referência no que tange à organização interna e às relações afetivas, e surge a questão: devem soli-darizar-se com Gregor ou fugir dele?

Nesse momento, todas as pessoas que participam do pequeno universo de Gregor não conseguem aceitá-lo, não podem aceitálo. Não só por sua aparência, mas também porque não fala como um humano, não tem hábitos humanos, e por conseqüência crêem elas - não deve sentir ou pensar como os homens. Gregor é cada vez mais um inseto peçonhento e asqueroso. Mesmo que o som do violino tocado pela irmã produza uma certa emoção, um certo encantamento e algumas lembranças, o antigo caixeiroviajante já não é mais um homem em sua plenitude. $E$ fica a pergunta: será que o fora antes da transformação?

A memória, de um indivíduo e de uma comunidade, é fundamental para a identidade e a história. Todavia, essa foge ao domínio de Gregor Samsa, que não consegue mais distinguir a realidade do puro delírio, pois sua nova vida de inseto fez com que perdesse sua identidade. Assim, não resta mais nada a Gregor além da morte, e sua morte, contudo, dará vitalidade à família.

Creio que nesse texto Kafka está concomitantemente tratando da história cotidiana das pessoas e inquirindo muitas das grandes categorias que forjaram as mentalidades moderna e contemporânea. Ao levar a crítica ao paroxismo, mergulha, por exemplo, no cotidiano dos homens do início do século XX, e nele coloca em xeque muitos dos pilares das sociedades ocidentais, a saber, categorias como sujeito, autonomia, igualdade, liberdade e racionalidade. É nessa perspectiva que, para além do otimismo científico e da ideologia do Estado de bem-estar social, percebe a normalização institucional dos indivíduos. E mais, discute os valores burgueses na família e as relações de sujeição no mundo do trabalho, ou ainda, a fixidez dos papéis sociais definidos pela assimetria que, cabe destacar, é rigidamente marcada pela hierarquia: o funcionário público, 0 pai, a irmã, a cozinheira (Albuquerque Junior 8:20-24). Daí a inquietude da questão que é recorrente na novela: será que Gregor fora um homem antes da metamorfose?

Kafka não é um escritor onírico. Assim, é possível dizer que a normalização característica de tantas instituições educacionais, de saúde, etc. - marcam a emergência histórica de novos e sofisticados processos de metamorfose. Também as Ciências Humanas, a influência do mercado capitalista nas relações de trabalho e os regimes totalitários - não sem distinções e variações - docilizaram os corpos individuais e geriram os corpos populacionais, promovendo metamorfoses nos comportamentos dos homens e mulheres do século XX. Por exemplo, a canalização de todas as forças humanas para 0 crescimento do capital, o ideal da poupança na família burguesa, a vinculação da identidade dos sujeitos à propriedade privada, a exploração no trabalho, o medo do desemprego e da conseqüente miséria ilustram aspectos importantes da banalização do absurdo cotidiano, discutido nas análises críticas de Kafka à luz da história.

Em A metamorfose, Kafka fala do estado de demência e putrefação do corpo burocrático presente em tantas instituições no início do século XX - quem sabe também em instituições de saúde a partir da modernidade. Este processo degenerativo despersonaliza os sujeitos e deteriora as relações intersubjetivas, fere princípios éticos e rejeita transformações sociais. Por fim, a dura constatação de Kafka que gera tanto desconforto, ou pelo menos deveria gerar: não há revolta ou resistência por parte de Gregor Samsa, só tristeza e conformismo. Vejo aqui Kafka discutindo as transformações do homem moderno e, assim, sua impotência em tantos momentos ante a lei e o poder. Gregor metamorfoseado, reificado, é o colapso do otimismo depositado na noção moderna de subjetividade. Em outros termos, o trabalho como valor absoluto, o quarto como refúgio, o corpo docilizado mostram que o "monstro humano" é também o homem produtivo constituído à imagem e semelhança da máquina - o homem autômato.

Em Na colônia penal, o pensador mostra a lógica perversa presente na vinculação entre os dispositivos legais da instituição 
penal e a incorporação da culpa. Desta forma, o soldado que não corresponde às expectativas, aceita a punição e sente-se envergonhado, mas desconhece os motivos. Ou seja, a culpa antecede a possível falta cometida. Como no texto anterior, Kafka desnuda a relação entre a produtividade e a sujeição expressa em tantas instituições contemporâneas.

Embora essa novela nos remeta a inúmeras possibilidades de análise a partir de diferentes matizes, quero aqui dar ênfase à máquina de tortura, um sofisticado instrumento que visava realizar a "justiça" da colônia penal. Explicando a anatomia da máquina, diz o oficial ao estrangeiro:

Como se vê, ele se compõe de três partes. Com o correr do tempo surgiram denominações populares para cada uma delas. A parte de baixo tem o nome de cama, a de cima, de desenhador, e a do meio, que oscila entre as duas, se chama rastelo (Kafka ${ }^{11: 32}$ ).

0 uso da máquina não é irracional. Isso porque ela é construída e legitimada com base num modelo de racionalidade. Todavia, a destruição da máquina no final da novela não significa, por exemplo, a vitória humanista ante a barbárie, mas possivelmente a emergência de novas e mais sofisticadas tecnologias de sujeição. Creio que uma analítica dos detalhes revelaria que, apesar de todo sangue derramado e de toda dor extraída daqueles sujeitados à máquina, ela é para tantos homens símbolo e sinônimo de limpeza, higiene e pureza. Assim, a máquina de tortura racionalmente projetada e calculada opera clivagens, hierarquias no espaço institucional. Isso em consonância com sua utilidade e objetividade.

Enfatizo a relevância de empreendermos, em nossos dias, no campo da saúde e nas pesquisas em história da enfermagem, a crítica às novas máquinas sociais - políticas e científicas - e aos seus efeitos, a exemplo da produtividade "objetivante" e "subjetivante" que sujeita os corpos individuais e sociais. É, desta forma, tarefa dos historiadores da Enfermagem a problematização dos efeitos das técnicas que escrevem o medo na carne humana, que criam indivíduos excessivamente governados, dóceis às estratégias de gestão e, assim, ao autoflagelo.

No detalhes e nas filigranas, no murmúrio da dor abafada, Kafka traria a surpresa não pelo fantástico, mas aquela provocada pelo real e exacerbada pelo real. Mais do que um desmascaramento de uma "naturalização" da morte e dos tormentos, a crueldade kafkiana parece lançar aos nossos olhos o incomodo enunciado de que os carrascos estão em diversos pontos, estão também em nós, estão em nossa vontade de aceitar o castigo, em nossa vontade de obedecer. $E$ o castigo está nos atos e nas carnes laceradas em permanente volta e atualização (Rodrigues ${ }^{12: 172}$ ).

Na novela, o suor das pessoas, o desconforto dos pesados uniformes que simbolizam a pátria distante, as altas temperaturas indicam que a colônia penal se localiza numa ilha tropical. Apesar de divergentes, os pontos de vista do estrangeiro e do comandante assumem ares de universalidade, sugerindo uma certa razão eurocêntrica ante as confusões dos filhos dos trópicos. Procurando superar preconceitos e estereótipos, mas sem reivindicar um purismo de origem, reafirmo nosso dever intelectual de não renunciarmos a teorizar sobre nós mesmos: enfermeiros, filósofos, etc. Para tanto, é condição sine qua non resgatarmos cada vez mais no campo da reflexão, como vêm fazendo os teóricos da Enfermagem, o vigor de nossas experiências históricas, culturais e políticas.

\section{APROXIMAÇÕES: HÁ CONTRIBUIÇÕES À PESQUISA EM HISTÓRIA DA ENFERMAGEM?}

No empreendimento de uma história crítica é possível aproximarmos Kafka e Foucault? Em que medida ambos podem contribuir metodologicamente para os já reconhecidos estudos na área da história da Enfermagem? Sem a pretensão de esgotar o tema, penso que, se evitarmos a presunção de desqualificar ou minimizar a importância de outras abordagens teóricas, bem como o entendimento de que sejam a genealogia foucaultiana e a crítica kafkiana a panacéia no campo das teorias da história, vislumbramos sim um profícuo campo de possibilidades de investigação dos objetos característicos da história da enfermagem.

A constituição histórica dos acontecimentos nas instituições de saúde, suas emergências e proveniências, os múltiplos olhares do "pesquisador-historiador" da Enfermagem, os diferentes matizes, as múltiplas perspectivas e o estranhamento dos objetos investigados podem servir, no exercício reflexivo da crítica, para colocar em xeque, por exemplo, a pseudo-segurança das áreas do conhecimento que outorgam a si mesmas o estatuto de cientificidade em detrimento de outras.

E mais, interpretar os objetos, demorar-se nos detalhes, empreender a analítica das fontes, dos conteúdos, recoloca o desafio do historiador da Enfermagem ante a pesquisa: é preciso não somente inquirir, mas também, e sobretudo, refletir, remastigar, remoer, em uma palavra, como sugerirá Nietzsche, "ruminar".

Penso que esta atitude epistemológica, mas também éticopolítica, revigora a experiência do saber histórico como, quem sabe, uma resistência não ressentida no campo do saber e das relações sociais. Como propunha Nietzsche, diferente da "reatividade decadente", o olhar do historiador sobre a vida, as marcas das suas mãos nos pergaminhos e a sua inserção no presente constituem-se decisivamente como possibilidades de "atividades investigativas". Por fim, descartando qualquer possibilidade de purismo cientificista, esta nova escrita da história pode transformar-se em campo de resistência social, viabilizando novos olhares sobre os fenômenos humanos cabe destacar que empresas como esta já fazem parte do universo próprio aos estudos em História da enfermagem. Creio que é nesse espírito que a escrita da história da Enfermagem pode fazer a crítica dos efeitos da racionalização científica, política e econômica e, assim, da sujeição dos corpos individuais e sociais, como também das múltiplas formas de absurdo toleradas por nossas instituições na atualidade. 


\section{Referências}

1. Nietzsche F W. Genealogia da moral: uma polêmica. Tradução de Paulo César de Souza. São Paulo (SP): Companhia das Letras; 1998.

2. Machado R. Nietzsche e a verdade. Rio de Janeiro (RJ): Rocco; 1999.

3. Nietzsche FW. Segunda consideração intempestiva: da utilidade e desvantagem da história para vida. Tradução de Marco Antônio Casanova. Rio de Janeiro (RJ): Relume Dumará; 2003.

4. Marton S. Foucault leitor de Nietzsche. In: Ribeiro RJ, organizador. Recordar Fou-cault. São Paulo (SP): Brasiliense; 1985.

5. Foucault M. Microfísica do poder. Tradução de Roberto Machado. Rio de Janeiro (RJ): Graal; 1990.

6. Foucault M. Em defesa da sociedade. Tradução de Maria Ermantina Galvão. São Paulo (SP): Martins Fontes; 1999.

7. Lebrun G. 0 microscópio de Michel Foucault. In: Lebrun G. Passeios ao léu. São Paulo (SP): Brasiliense; 1983.
8. Albuquerque Junior DM. No castelo da história só há processos e metamorfoses, sem veredicto final. In: Passetti E, organizador. Kafka, Foucault: sem medos. São Paulo (SP): Ateliê; 2004.

9. Kafka F. A metamorfose. Tradução de Modesto Carone. São Paulo (SP): Companhia das Letras; 1997.

10. Schwarz R. A sereia e o desconfiado. Rio de Janeiro (RJ): Paz e Terra; 1981.

11. Kafka F. $O$ veredicto e na colônia penal. Tradução de Modesto Carone. São Paulo (SP): Companhia das Letras; 2004.

12. Rodrigues, T. Uma mecânica da dor: Kafka, Foucault e o horror ao horror. In: Passetti E, organizador. Kafka, Foucault: sem medos. São Paulo (SP): Ateliê; 2004.

\section{Nota}

${ }^{a}$ Esse Ensaio é resultado da conferência proferida no $2^{\circ}$ Colóquio Latino-Americano de História da Enfermagem ( $2^{\circ}$ COLAHE). 